\title{
ANKYLOSING SPONDYLITIS SIMULTANEOUS TO HEREDITARY MULTIPLE EXOSTOSES - RELATED ETIOPATHOGENESIS OR MERELY A COINCIDENCE?
}

Cauê José Pedroso Pinheiro da Silva (Universidade Estadual do Oeste do Paraná, Cascavel, PR, Brasil), Luisa Manfredin Vila (Universidade Estadual do Oeste do Paraná, Cascavel, PR, Brasil), Andressa Caroline Kuzma (Universidade Estadual do Oeste do Paraná, Cascavel, PR, Brasil), Julia Deitos (Universidade Estadual do Oeste do Paraná, Cascavel, PR, Brasil), Victor Vinicius Unfried da Luz (Universidade Estadual do Oeste do Paraná, Cascavel, PR, Brasil), Júlia Natsumi Hashimoto (Universidade Estadual do Oeste do Paraná, Cascavel, PR, Brasil), Lorena Vaz Meleiro Lopes (Universidade Estadual do Oeste do Paraná, Cascavel, PR, Brasil), Jackson Danrlei Balbinot (Universidade Estadual do Oeste do Paraná, Cascavel, PR, Brasil), Lucas Thiesen Pientka (Universidade Estadual do Oeste do Paraná, Cascavel, PR, Brasil), Ana Paula Adame (Universidade Estadual do Oeste do Paraná, Cascavel, PR, Brasil), Marcio Augusto Nogueira (Universidade Estadual do Oeste do Paraná, Cascavel, PR, Brasil)

\section{BACKGROUND}

Only four cases of simultaneous Ankylosing Spondylitis (AS) and Hereditary Multiple Exostoses (HME) have been reported. AS is a chronic inflammatory disorder of the axial skeleton, affecting 7:100.000 people per year, associated with the HLA-B27 antigen. HME is an autosomal dominant disease, linked to the EXT1 and EXT2 genes, in which multiple exostoses grow on bone metaphysis through endochondral ossification. This condition can affect the growth plaque, causing deformity of the limbs, low stature and scoliosis, besides neurovascular complications. Its estimated prevalence is $1: 50.000$, and it's more common and more limiting in males.

\section{CASE REPORT}

A 12-year-old male was referred to a tertiary hospital, presenting with cervical, thoracic and lumbar pain for 3 months, difficulty walking, morning stiffness and a restricted range of motion (ROM), besides multiple painful nodules throughout the body since the age of one. His father has similar lesions. On the physical examination, there was reduced ROM of the axial skeleton and sacroiliac joints, reduced thoracic expandability, and pain on palpation of the intercostal spaces, besides bony prominences of various sizes, in various parts of the body. On further laboratory studies, a high erythrocyte sedimentation rate and mild anemia were found. Radiography of the nodules suggested benign bone growths in metaphysis. Magnetic resonance imaging of the sacroiliac joints revealed sacroiliitis. Based on those findings, we arrived at the diagnosis of AS and HME. The patient is currently being treated with indomethacin and sulfasalazine, with plans to start anti-TNF therapy.

\section{CONCLUSION}

The incidences of both AS and HME are very low, and their concomitance is an even rarer event. More studies are needed in order to clarify whether there is an etiologic correlation regarding those diseases, or whether its coexistence is mere coincidence. The knowledge regarding the presentation of both diseases is of utmost importance, seeing as both are chronic, progressive disorders, and their late diagnosis can cause irreversible damage. 